\title{
Electrical Properties of Plasma-Polymerized Thin Films
}

\author{
Yun Heum PARK, * Hiroaki TsuTsumI, Shigeru TASAKA, \\ and Seizo MIYATA \\ Department of Material Systems Engineering, Faculty of Technology, \\ Tokyo University of Agriculture and Technology, \\ Nakamachi, Koganei, Tokyo 184, Japan
}

(Received September 7, 1985)

\begin{abstract}
Thin organic polymer films were prepared by plasma polymerization in the heated system. The films obtained were very smooth and free of pinholes. The electrical conductivities ranged from $10^{-6}$ to $10^{-7} \mathrm{~S} \mathrm{~cm}^{-1}$ and the $\mathrm{Al} / \mathrm{Polymer} / \mathrm{Au}$ cells with polymers produced from fumaronitrile and $p$-aminobenzonitrile showed rectifying effect. Both IR observations and electrical measurements confirmed that the conjugated double bonds formed by plasma polymerization in the heated system were responsible for high electrical conductivity. The plot of $\log \sigma$ vs. $1 / T$ gave straight line and $0.29 \mathrm{eV}$ of the activation energy was determined for fumaronitrile polymer.
\end{abstract}

KEY WORDS Plasma Polymerization / Electrical Conductivity / Fumaronitrile / Isophthalonitrile / p-Aminobenzonitrile / Organic Semiconductor /

The formation of thin polymer films by means of the glow discharge in the vapor of a monomer at low pressure, referred to as plasma polymerization, has been well known for many years. ${ }^{1}$ Because of the large number of reaction pathways available during plasma polymerization, the polymers generally have very complex structures such as branching or formation of new groups. The major distinguished feature in them is the very high degree of crosslinking which renders them insoluble. ${ }^{2,3}$

As the plasma-polymerized films have generally the characteristics of high electrical resistivity and strong adhesion to substrates, the plasma polymerization technique has become widely accepted in the electronics and optics manufacturing industries; plasma polymers have been used as dielectrics for thin film capacitors, ${ }^{4,5}$ protection of semi- conductor devices, ${ }^{6,7}$ chemically modified electrodes, ${ }^{8-11}$ scratch resistant coatings for plastic optical components, ${ }^{12}$ optical waveguides, ${ }^{13}$ antireflection coatings, ${ }^{12}$ and coatings for the orientation of liquid crystals in liquid crystal displays. ${ }^{14}$ Less directly, plasma polymers have found application as corrosion protective coatings for metals or alloys. ${ }^{15}$

The glow discharge process in most investigation was carried out at room temperature and the conductivity of plasma polymers obtained ranged from $10^{-17}$ to $10^{-13} \mathrm{~S} \mathrm{~cm}^{-1}$. In the previous study ${ }^{16}$ in our laboratories, acetonitrile was plasma-polymerized at room temperature and then the polymer film was annealed at the temperature ranging from 200 to $500^{\circ} \mathrm{C}$ in a vacuum. It was found that the electrical conductivity increased by annealing, ranged from $10^{-10}$ to $10^{-3} \mathrm{~S} \mathrm{~cm}^{-1}$, but this technique has the following draw-

\footnotetext{
* Permanent address: Department of Textile Engineering, Sung Kyun Kwan University, Su Won, Korea.
} 
backs; one is the fact that two fabricating processes, plasma-polymerization and annealing, are needed for an electrically conductive film and the other is that pinholes and/or cracks in a polymer film are susceptible to formation because of the evaporation of the low molecular fragments and foreign materials during the annealing process.

In the present work, we plasma-polymerized some monomers containing cyanogen groups in a heated system for the improvement of above-mentioned drawbacks and investigated the electrical properties of plasma polymer films sandwiched between metal electrodes.

\section{EXPERIMENTAL}

\section{Plasma Polymerization}

Figure 1 shows a schematic diagram of plasma polymerization reactor. The outside of the reactor whose body is $5 \mathrm{~cm}$-i.d. Pyrex glass of $60 \mathrm{~cm}$ length was heated to $250^{\circ} \mathrm{C}$ with a mantle heater. The inside was evacuated to $10^{-2}$ torr with a rotary pump and then the glass substrate with a predeposited gold electrode was heated to $200^{\circ} \mathrm{C}$ with an inner heater. Before the gold predeposition the glass substrate was cleaned by sonification and rinsed with copious amount of distilled water. The solid monomer mounted on another inner heater was heated to near its melting point and the vapor pressure of monomer was around 1 torr. All monomers of fumaronitrile, isophthalonitrile, and $p$-aminobenzonitrile were reagent grade and used as obtained from the manufacturer (Tokyo Kasei Co.). The glow discharge was initiated at $10-100 \mathrm{~W}$ by a Tokyo Hy-power's rf power signal generator (model PSG-1301) which operates at $13.56 \mathrm{MHz}$. Radio frequency was coupled to a glow discharge capacitively by use of two parallel aluminum plates, placed outside to glow discharge vessel and $7 \mathrm{~cm}$ apart.

\section{Sandwich Cell Preparation}

The specimen was removed from the plasma chamber and the top electrode was evaporated on the plasma-polymerized films in a vacuum of about $10^{-6}$ torr using a JEOL JEE-4X Vacuum evaporator. The aluminum mask was utilized to restrict the area of top electrode to approximately 0.1 square centimeter. When aluminum lead wires were attached at the ends of the specimen with the aid of silver paste it was ready for electrical measurements. The configuration of sandwich cell is shown in Figure 2.

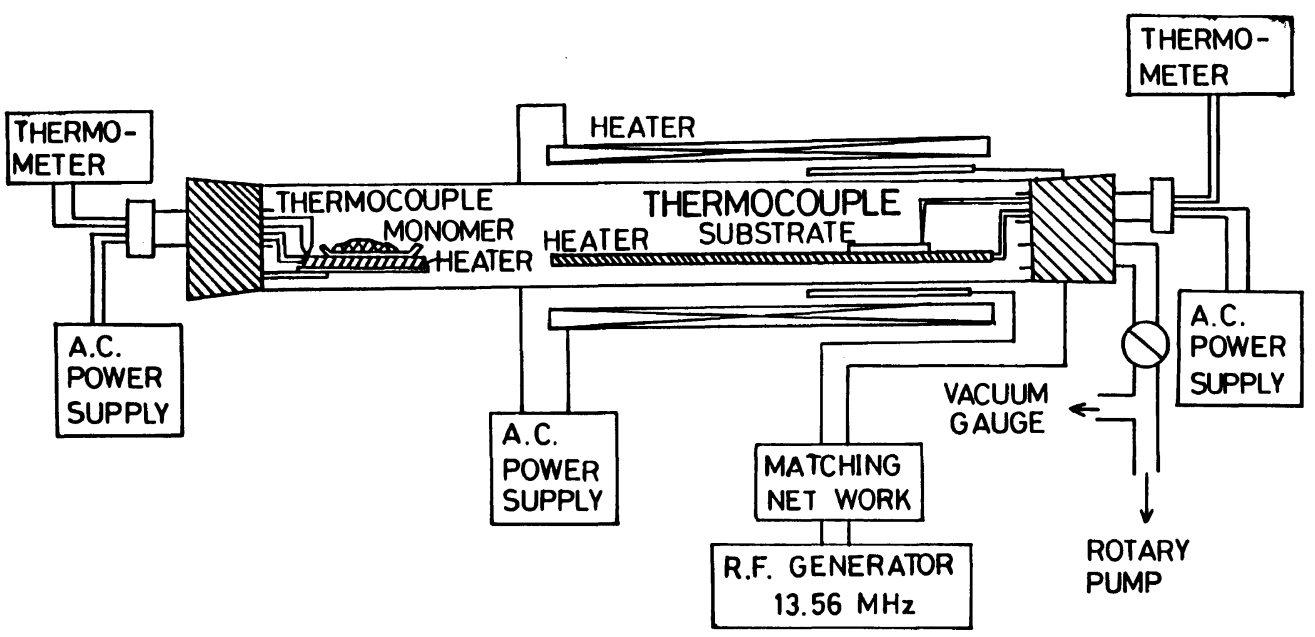

Figure 1. Schematic diagram of plasma polymerization reactor. 

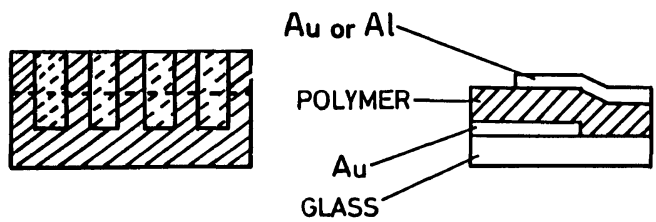

Figure 2. Configuration of sandwich cell.

\section{Electrical Measurements}

Current-voltage measurements were carried out using an electrometer (TR-8641, Takeda Riken) and a DC voltage supply (Type 2553, Yokogawa Electric Works, Ltd.) or a function generator (model FG-121B, NF Circuit Design Block Co., Ltd.) which generates the triangular voltage. The voltage across the sample capacitor was slowly increased manually or automatically and the output was fed to the $\mathrm{X}$-axis of an X-Y recorder (model F-3F, Riken Denshi Co. Ltd.). Simultaneously, the current was observed on the $\mathrm{Y}$-axis.

\section{Film Thickness Measurement}

The thickness determination of the polymer films was done by a multiple interference unit attached to metallurgical microscope (Nikon Optiphoto, type 104). The thickness of the plasma polymerized films ranged between $1000 \mathrm{~A}$ to $1 \mu \mathrm{m}$.

\section{IR Spectra}

Infrared absorption spectra of polymer films deposited on metal-coated slide glasses were recorded by polarized refrection method in IR spectrometer (DS-701G + PR-51, JASCO).

\section{Scanning Electron Micrograph}

The electron micrograph was taken with a JEOL JSM-25S III scanning electron microscope. The polymer film was coated with gold by the sputter deposition prior to the measurement in order to improve the resolution of the micrograph.

\section{RESULTS AND DISCUSSION}

In the heated plasma-polymerization system

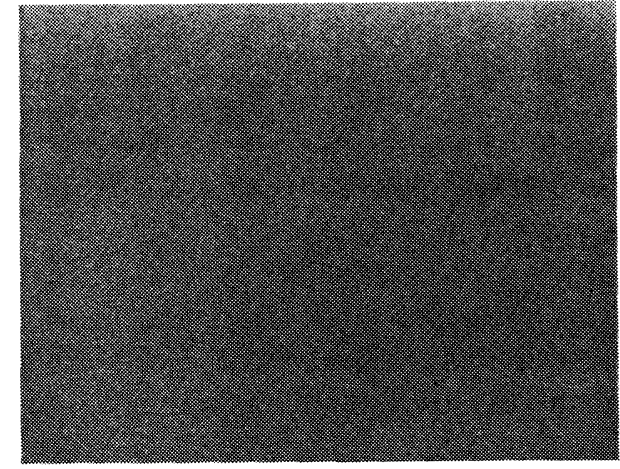

Figure 3. SEM photograph of fumaronitrile polymer film $(\times 10000)$.

any volatile foreign materials or low molecular fragments are evaporated from the substrate and sucked into the vacuum trap during the plasma-polymerization process. Holes or thin spots resulting from the evaporation of volatile foreign materials or low molecular fragments in polymer films are filled with high molecular fragments or polymer due to the stronger electrical field at holes or thin spots. This film-formation process continues for the given polymerization time and consequently very uniform and pinhole-free films can be obtained. Figure 3 shows a SEM photograph of fumaronitrile polymer (FN) film. The polymer film is very smooth and pinholefree. In fact it was so smooth that it was difficult to obtain good resolution. Several investigators ${ }^{13,17-20}$ have examined plasmaformed polymers with SEM and observed spherical powders with diameters of a few microns. However, no such particles were observed in the films produced here.

The polymer films adhered tightly to their substrates and showed no dissolution in a variety of solvents such as water, methanol, dichloromethane, acetonitrile, and tetrahydrofuran. Strong adhesion to a substrate might be ascribed to the formation of highly reactive free radicals on the surface of substrate by the bombardment of radiation of various wavelengths produced by the plasma. Such highly reactive radicals could contribute 
to bond formation between substrate and growing polymer. By the use of electron spin resonance, Morosoff et al. ${ }^{21}$ have detected the presence of free radicals in a glass substrate subjected to plasma treatment or plasma coating.

Inferring from the fact of insolubility in organic solvents and the mechanism of plasma polymerization, the polymer was thought to have highly crosslinked structure.

Table I shows the electrical properties of the polymers produced at $200^{\circ} \mathrm{C}$ in the heated system. The electrical conductivities, which were measured with $\mathrm{Au} / \mathrm{Polymer} / \mathrm{Au}$ cells, ranged from $10^{-6}$ to $10^{-7} \mathrm{~S} \mathrm{~cm}^{-1}$ and were enhanced by one order of magnitude by $13 \mathrm{~mW} \mathrm{~cm} \mathrm{~cm}^{-2}$ of white light excitation. The polymer films which showed high electrical conductivities compared to the results of Bradley et al., ${ }^{1} 10^{-17}-10^{-13} \mathrm{~S} \mathrm{~cm}^{-1}$, would qualify for consideration as organic semiconductors.

The Al/Polymer/Au cells with FN and with PABN showed the rectifying effect. The cell with IPN exhibited no rectifying effect, but it showed a blocking contact, which gave nonsymmetrical and non-ohmic characteristics. It may be due to the existence of the surface potential in the IPN.

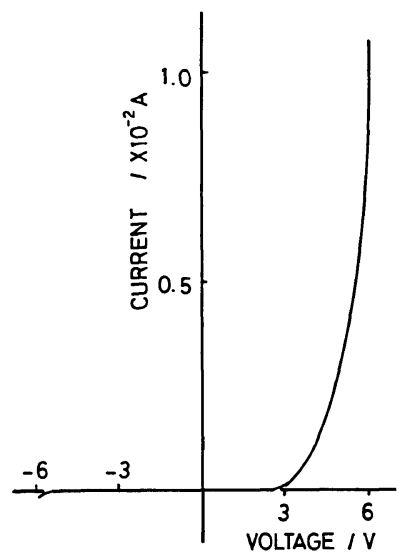

Figure 4. Current-voltage characteristic for $\mathrm{Al} / \mathrm{FN} / \mathrm{Au}$ cell.
Figure 4 shows a typical current-voltage characteristic of $\mathrm{Al} / \mathrm{FN} / \mathrm{Au}$ cell when biased on the Al electrode. This polymer is $p$-type semiconductor from the measurement of thermoelectric effect (Seebeck effect). Therefore, the polymer can form Schottky barrier with aluminum which has low work function. The direction of the forward current and the large rectification ratio suggest the formation of the Schottky barrier at the $\mathrm{Al} / \mathrm{FN}$ interface. In addition, the capacitance of the cell depends slightly on the bias electric field. The carrier density of the polymer which was evaluated from the bias field dependence of capacitance $\left(1 / c^{2}\right)$ was about $10^{-17} \mathrm{~cm}^{-3}$. This means the polymers have the low carrier mobility, which is responsible for amorphous structure of the polymer. The forward current-voltage characteristic is represented by the following relationship. ${ }^{22}$

$$
J \simeq J_{s} \exp (q V / n k T)
$$

where $J$ is a current density, $J_{\mathrm{s}}$ the saturation current density, $q$ the charge of an electron, $V$ an applied voltage, k the Boltzmann constant, $T$ an absolute temperature, and $n$ an ideality factor defined as

$$
n \equiv(q / k T) \cdot(\partial V / \partial(\ln J))
$$

In organic devices, $n$ implies the deviation from ideal diode $(n=1)$. The values of $n$ for organic devices were reported as 1.5 for phthalocyanines, ${ }^{23} 1.98$ for polyacetylene, ${ }^{24}$ and 5.0 for poly( $p$-phenylene sulfide). ${ }^{25}$ As shown in Table I, the present devices show-

Table I. Electrical properties of the sandwich cells

\begin{tabular}{lccc}
\hline $\begin{array}{c}\text { Plasma } \\
\text { polymer }\end{array}$ & $\begin{array}{c}\text { Rectification } \\
\text { ratio at 5 V }\end{array}$ & $\begin{array}{c}\text { Ideality } \\
\text { factor }\end{array}$ & $\begin{array}{c}\text { Conductivity } \\
\mathrm{S} \mathrm{cm}^{-1}\end{array}$ \\
\hline FN & $100-200$ & $6-8$ & $10^{-6}$ \\
IPN & - & - & $10^{-7}$ \\
P-ABN & $50-100$ & $12-17$ & $10^{-6}$ \\
\hline
\end{tabular}

a FN, IPN, and P-ABN represent the plasma polymer produced from fumaronitrile, isophthalonitrile, and $p$ aminobenzonitrile, respectively. 


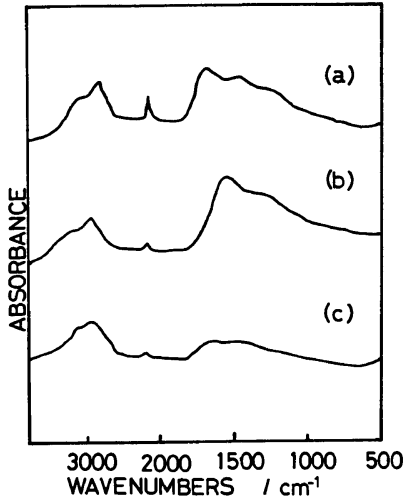

Figure 5. IR spectra of FN Polymer; (a) polymerized at room temperature $\times 10 \mathrm{~W}$, (b) $200^{\circ} \mathrm{C} \times 10 \mathrm{~W}$, (c) room temperature $\times 100 \mathrm{~W}$.

ed the slightly higher $n$ values as organic devices. This might be due to the high concentration of trap levels in the polymer/ electrode interface and polymer bulk.

Figure 5 shows the IR spectra of FN. They represent the spectra of the samples, (a) subjected to glow discharge at room temperature and $10 \mathrm{~W},(\mathrm{~b})$ at $200^{\circ} \mathrm{C}$ and $10 \mathrm{~W}$ in the heated system, and (c) at room temperature and $100 \mathrm{~W}$. The general feature of the spectra peaks was similar and all showed an unresolved distribution of absorption bands, suggesting a mixture of materials with extended conjugation or free valences. In comparison with (a) and (b), the intensity of the absorption peak at $2200 \mathrm{~cm}^{-1}(\mathrm{C} \equiv \mathrm{N}$ stretching vibration) was weaker in (b) and the peak at 1670 $\mathrm{cm}^{-1}$ (nonconjugated $\mathrm{C}=\mathrm{C}$ and/or $\mathrm{C}=\mathrm{N}$ stretching vibration) shifted to $1600 \mathrm{~cm}^{-1}$ (conjugated $\mathrm{C}=\mathrm{C}$ and/or $\mathrm{C}=\mathrm{N}$ stretching vibration). In the other comparison with (a) and (c), the peaks at 2200 and $1670 \mathrm{~cm}^{-1}$ are weaker in (c). The electrical conductivities of sample (a) and (c) were the order of $10^{-12} \mathrm{~S}$ $\mathrm{cm}^{-1}$, but the electrical conductivity of (b) was the order of $10^{-6} \mathrm{~S} \mathrm{~cm}^{-1}$. From these results it can be suggested that the effects of temperature and power are both related to the opening of $\mathrm{C} \equiv \mathrm{N}$ bond, but the temperature has influenced to the formation of conjugated

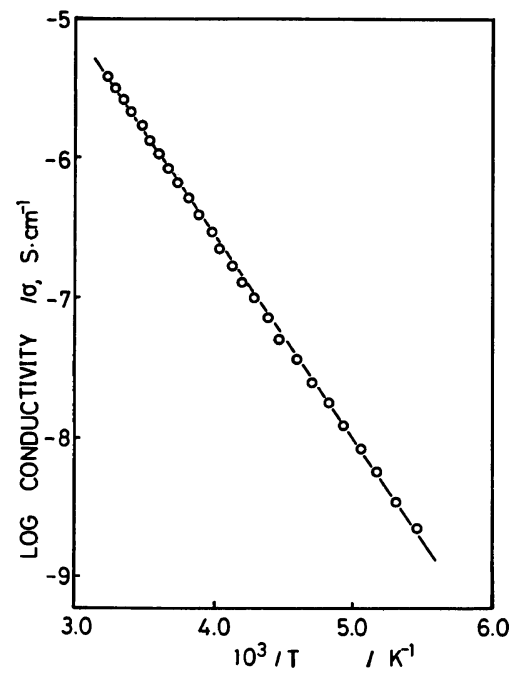

Figure 6. $\log \sigma$ vs. $10^{3} / T$ plot for FN Polymer at $2.0 \mathrm{~V}$.

double bond which can form bands by overlapping $\pi$-orbitals and through which the transport of electrons or holes can occur, resulting in high conductivity. The reproducible results of electrical properties can be obtained with the sample polymerized in the heated system, but in the case of samples polymerized at the room temperature and then annealed above $200^{\circ} \mathrm{C}$ they cannot be obtained.

The stability of the polymer films made it possible to measure an activation energy of electrical conduction. The temperature dependence of the electrical conductivity of FN is shown in Figure 6. The conductivity was related to the familiar expression ${ }^{26}$

$$
\sigma=\sigma_{0} \exp \left(-E_{\mathrm{a}} / k T\right)
$$

in which $E_{\mathrm{a}}$ is the activation energy for conduction, $\sigma$ electrical conductivity and $\sigma_{0}$ constant. The activation energy was calculated to be $0.29 \mathrm{eV}$ from the slope of the straight line in Figure 6 and the energy band gap, $E_{\mathrm{g}}, 0.58$ $\mathrm{eV}$ from the equation ${ }^{27}$ of $E_{\mathrm{g}}=2 E_{\mathrm{a}}$, derived from the assumption of an intrinsic semiconductor. The low activation energy in the present investigation showed remarkable contrast 
to the value of $1.36 \mathrm{eV}$ reported by Bradley et $a .^{28}$ who had plasma-polymerized hydrocarbon and amine monomers at room temperature. This implies a different conductivity mechanism, one of the possibilities must be that in the present polymer the principle charge carriers are available from conjugated carbon-nitrogen double bonds where the mobility might be higher, while in the hydrocarbon and amine polymers the charge transfer is due to hopping along the carbon-carbon skeleton.

\section{CONCLUSION}

Thin organic polymer films produced by plasma polymerization in the heated system are smooth and free of pinholes, and showed no dissolution in a variety of solvents. Films have $10^{-6}-10^{-7} \mathrm{~S} \mathrm{~cm}^{-1}$ of electrical conductivities which are influenced by the presence of the conjugated double bonds and consequently would qualify for consideration as organic semiconductors. The low activation energy compared to the results of Bradley et $a{ }^{1}{ }^{1}$ indicates that the principle charge carriers are available from conjugated carbon-nitrogen double bonds.

Acknowledgement. This work was partly supported by the Grant-in-Aid on Special Project Research for "Organic Thin Films for Information Conversion" from the Ministry of Education, Science and Culture, and by Chemical Materials Research \& Development Fundation (Johnson Foundation).

\section{REFERENCES}

1. A. Bradley and J. P. Hammes, J. Electrochem. Soc., 110, 15 (1963).

2. J. M. Tibbitt, M. Shen, and A. T. Bell, J. Macromol. Sci.-Chem., A10, 1623 (1976).

3. S. Kaplan and A. Dilks, J. Appl. Polym. Sci. Sym.,
38, 105 (1984).

4. H. Pachonik, Thin Solid Films, 38, 171 (1976).

5. J. M. Tibbit, A. T. Bell, and M. Shen, J. Macromol. Sci.-Chem., A10, 519 (1976).

6. A. Bui, H. Carchano, and D. Sanchez, Thin Solid Films, 13, 207 (1972).

7. M. Maisonneuve, Y. Segui, and A. Bui, Thin Solid Films, 33, 35 (1976).

8. R. Nowak, F. A. Schultz, M. Umana, H. Abruna, and R. W. Murray, J. Electroanal. Chem., 94, 219 (1978)

9. P. Daum, J. R. Lenhard, D. Rolison, and R. W. Murray, J. Am. Chem. Soc., 102, 4649 (1980).

10. R. J. Nowak, F. A. Schultz, M. Umana, R. Lam, and R. W. Murray, Anal. Chem., 52, 315 (1980).

11. P. Daum and R. W. Murray, J. Electroanal. Chem., 103, 289 (1979).

12. T. Wydeven, Appl. Opt., 16, 717 (1977).

13. P. K. Tien, G. Smolinsky, and R. J. Martin, Appl. Opt., 11, 637 (1972).

14. G. J. Sprokel and R. M. Gibson, J. Electrochem. Soc., 124, 557 (1977).

15. D. F. O'kane and D. W. Rice, J. Macromol. Sci.Chem., A10, 567 (1976).

16. S. Suzuki, S. Tasaka, and S. Miyata, Kobunshi Ronbunshu, 41, 493 (1984).

17. M. R. Havens, K. G. Mayhan, and W. J. James, J. Appl. Polym. Sci., 22, 2799 (1978).

18. H. Kobayashi, A. T. Bell, and M. Shen, J. Appl. Polym. Sci., 29, 2617 (1984).

19. H. Kobayashi, A. T. Bell, and M. Shen, Macromolecules, 7, 277 (1974).

20. H. Kobayashi, M. Shen, and A. T. Bell, J. Macromol. Sci.-Chem., A8, 373 (1974).

21. N. Morosoff, B. Crist, M. Bumgarner, T. Hsu, and H. Yasuda, J. Macromol. Sci.-Chem., A10, 451 (1976).

22. S. M. Sze, "Physics of Semiconductor Devices," A Wiley-Interscience Publication, New York, 1981, p 264.

23. F. R. Fan, L. R. Faulkner, J. Chem. Phys., 69, 3334 (1978).

24. P. M. Grant, T. Tani, W. D. Gill, M. Krounbi, and T. C. Clarke, J. Appl. Phys., 52, 869 (1981).

25. K. Misoh, S. Tasaka, and S. Miyata, Polym. Prepr., Jpn., 31 (10), 2755 (1982).

26. D. A. Seanor, "Electrical Properties of Polymers," Academic Press, New York, 1982, p 147.

27. D. A. Seanor, "Electrical Properties of Polymer," Academic Press, New York, 1982, p 188.

28. A. Bradley and J. P. Hammes, J. Electrochem. Soc., 110, 15 (1963). 